\title{
Improvement of abnormal lactulose/rhamnose permeability in active Crohn's disease of the small bowel by an elemental diet
}

\author{
I R SANDERSON, P BOULTON, I MENZIES, AND J A WALKER-SMITH \\ From the Department of Child Health, St Bartholomew's Hospital, and the Institute of Child Health, and the \\ Department of Chemical Pathology, St Thomas' Hospital, London
}

SUMMARY Intestinal permeability to sugar has been used as an objective measure of small bowel integrity to assess the efficacy of an elemental diet as the sole treatment or Crohn's disease of the small bowel. Fourteen children aged 11-17 years with active small bowel Crohn's disease were given an elemental diet for six weeks. Investigations with iso-osmolar oral test solutions before and after this treatment showed that all 14 children had abnormally raised lactulose/L-rhamnose permeability ratios, which fell significantly after the elemental diet. This change coincided with marked clinical improvement, as assessed by a disease activity index score.

An elemental diet is as effective as high dose steroids in inducing a remission in small bowel Crohn's disease both in adults' and in children, ${ }^{2}$ as judged by clinical assessment, a disease activity index score, ESR, CRP, and serum albumin. Elemental diets also reduce the amount of protein loss from inflamed bowel. ${ }^{3}$ The efficacy of an elemental diet, however, has never been evaluated using an objective index of small bowel integrity. Intestinal permeability can be assessed non-invasively with sugar markers and is abnormal in diseases which affect the morphology of the small intestine such as coeliac disease, ${ }^{+}$gastroenteritis ${ }^{5}$ and cow's milk hypersensitivity. ${ }^{5}$ Sugar permeability has also been shown to be abnormal in active Crohn's disease. ${ }^{\circ}$

The aim of this study was to determine what effect, if any, the administration of an elemental diet has upon intestinal sugar permeability tests in children with active Crohn's disease of the small bowel.

\section{Methods}

PATIENTS

Children who were in need of therapy for active Crohn's disease of the small bowel were chosen from

Address for correspondence: Dr I R Sanderson, Oueen Elizabeth Hospital for Children, Hackney Road, London E2 8PS.

Received for publication 12 February 1987 the Paediatric Inflammatory Bowel Disease Clinic at St Bartholomew's Hospital, London. The diagnosis was based upon their clinical features, barium follow through, and ileal histology from biopsies taken at colonoscopy.? A Lloyd-Still disease activity index score $^{x}$ was obtained before treatment began (Table 1) and assessed again after six weeks. The percentage score (a normal child scoring 100 points) is made up as follows: symptoms - 10; radiology -15 ; examination - 30; haemoglobin white cell count, albumin, ESR - 25; height and weight -20 . Making a total of 100 points. Radiology was not repeated after six weeks and so was not included in assessing any change over the six week period. Seven of the children with active disease were on steroids at the time of their attendance at the clinic. The dosage was reduced when put on the elemental diet (Table 1). Six children (Table 2) referred as suspected chronic inflammatory bowel disease were also studied. After investigation including colonoscopy, they proved to have no recognisable disease in small intestine and acted as controls.

ELEMENTAL DIET

The children with active Crohn's disease of the small bowel were given an elemental diet, Flexical ${ }^{R}$ (Bristol-Myers) through a nasogastric tube; ${ }^{2}$ the daily amount was determined using the recommended 
Table 1 Sex, age, Lloyd-Still disease activity score and Prednisolone therapy before and after treatment with an elemental diet

\begin{tabular}{llllll}
\hline & & & & \multicolumn{2}{c}{$\begin{array}{c}\text { Prednisone mean } \\
\text { dailydoselmg }\end{array}$} \\
\cline { 5 - 6 } Name & Sex & Age & Score & (Before) & (6 weeks) \\
\hline PD & M & $11 \cdot 2$ & 67 & 0 & 0 \\
AN & F & $11 \cdot 4$ & 48 & 0 & 0 \\
MD & F & $11 \cdot 9$ & 58 & 10 & $1 \cdot 25$ \\
MC & M & $12 \cdot 6$ & 67 & $7 \cdot 5$ & 0 \\
CC & F & $12 \cdot 7$ & 38 & 0 & 0 \\
AM & M & $12 \cdot 8$ & 75 & 10 & $3 \cdot 75$ \\
MD & M & $12 \cdot 8$ & 62 & 0 & 0 \\
KC & M & $13 \cdot 3$ & 68 & 0 & 0 \\
MV & M & $13 \cdot 8$ & 51 & 25 & 10 \\
LP & M & $14 \cdot 5$ & 56 & 0 & 0 \\
JH & F & $15 \cdot 2$ & 66 & 30 & 10 \\
GH & M & $15 \cdot 9$ & 75 & 20 & $3 \cdot 25$ \\
PH & M & $16 \cdot 0$ & 63 & 0 & 0 \\
DB & F & $17 \cdot 2$ & 57 & $13 \cdot 75$ & 0 \\
\hline
\end{tabular}

daily allowance based on the age of the child. ${ }^{9}$ They were otherwise given nil by mouth for six weeks and then foods were introduced sequentially in a controlled manner. ${ }^{2}$

\section{SUGAR PERMEABILITY STUDIES}

After an overnight fast of six hours a $80 \mathrm{ml}$ solution containing $5 \cdot 25 \mathrm{~g}$ of lactulose and $0.75 \mathrm{~g}$ of rhamnose $(260 \mathrm{mmol} / \mathrm{kg}$ ) was given to the child. All the urine passed in the subsequent five hours was collected, the volume recorded and an aliquot preserved with merthiolate $(100 \mathrm{mg} / 100 \mathrm{ml}$ minimum $)$ for analysis.

Urine sugars were estimated by quantitative thin layer chromatography."' After development of duplicate chromatograms using appropriate solvent systems, and a four aminobenzoic/phosphoric acid colour reaction, peak heights of the separated sugar zones were measured by scanning densitometry and corrected to a constant internal standard value. Sugar concentrations were then read by interpolation from standard curves plotted from the same chromatogram. Details of the technique and modifications used are given elsewhere. "'" The method is accurate and sensitive, and precision between 2 and $8 \%$

Table 2 Sex, age and reason for referral of children who acted as controls

\begin{tabular}{llrl}
\hline Name & Sex & Age & Diagnosis \\
\hline TE & F & $8 \cdot 9$ & Juvenile rectal polyp \\
PM & M & $11 \cdot 1$ & Recurrent abdominal pain of childhood \\
SGS & M & $13 \cdot 2$ & Recurrent abdominal pain of childhood \\
KH & F & $14 \cdot 7$ & Recurrent abdominal pain of childhood \\
HS & F & $15 \cdot 6$ & Ulcerative colitis \\
HS & F & $15 \cdot 6$ & Ulcerative colitis \\
SH & M & 17.9 & Crohn's colitis \\
\hline
\end{tabular}

(coefficient of variation) without replication over the concentration range encountered." Intestinal lactulose/rhamnose permeation was expressed as a ratio of the ingested dose for each sugar excreted in the five hour urine collection.

\section{STATISTICAL ANALYSIS}

Results were analysed using the paired Student's $t$ test.

\section{Results}

The six control children in whom chronic inflammatory bowel disease had been excluded had lactulose/ rhamnose permeability ratios within the normal range (Figure) as delineated in healthy children by Beach et al ${ }^{\prime 2}(0 \cdot 04 \pm 0 \cdot 01$, mean \pm standard deviation, ratio of percentage of oral dose excreted in five hour urine).

All 14 children with Crohn's disease of the small bowel showed an abnormally raised sugar permeability ratio $(0 \cdot 256 \pm 0 \cdot 037)$ before treatment. After

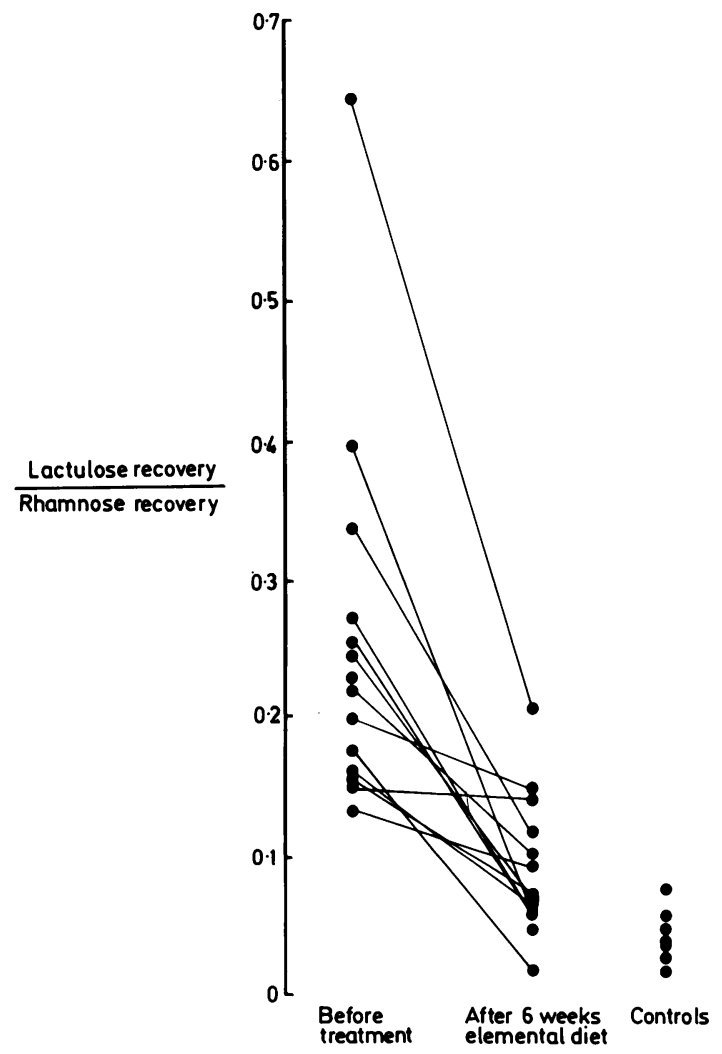

Figure Lactulose rhamnose ratios in 14 children with active Crohn's disease of the small bowel before and after a six week period of feeding with an elemental diet. 
treatment with an elemental diet there was a significant fall $(\mathrm{p}<0.001)$ in the sugar permeability ratio in all children to $0 \cdot 093 \pm 0 \cdot 012$ (Figure) despite receiving no other added therapy. Seven of the patients had lactulose/rhamnose permeability ratios within the normal range after six weeks dietary therapy.

The improvement in the intestinal permeability corresponded with other indices of disease activity such as the ESR, body weight and Lloyd-Still disease activity index (Table 3 ).

\section{Discussion}

Although the pathways of intestinal sugar permeation and mechanisms of altered permeability have not yet been fully characterised, ${ }^{13}$ the ratio of unmediated disaccharide/monosaccharide permeation is known to be raised in conditions associated with small intestinal mucosal damage such as coeliac disease ${ }^{41+}$ tropical sprue, ${ }^{15}$ and rotavirus enteritis. ${ }^{11}$ A correlation between morphological changes in the small intestinal mucosa and the lactulose/rhamnose permeability ratio has also been shown, ${ }^{5}$ and differential sugar permeation is now widely used as an objective index of small intestinal integrity..$^{13}$

Abnormal intestinal permeability to sugar markers was first demonstrated in Crohn's disease by Pearson et $a l^{6}$ who noted a relative increase in the permeation of lactulose compared with that of mannitol. A comparable abnormality has been demonstrated during the present study, all untreated patients having lactulose/rhamnose permeability ratios above the normal range. It is of interest that those children with chronic inflammatory bowel disease confined to the large intestine had permeability ratios within the normal range as defined by Beach et al, ${ }^{12}$

Table 3 Changes in indicators of disease activity over the six weeks on an elemental diet

\begin{tabular}{llll}
\hline & \multicolumn{3}{c}{ Changes over the six week period of elemental diet } \\
\cline { 2 - 4 } & $\begin{array}{l}\text { Diseaseactivity } \\
\text { score }(\%)\end{array}$ & ESR $(\mathrm{mm} / \mathrm{h})$ & Weight $(\mathrm{kg})$ \\
& +18 & -30 & \\
\hline PD & +32 & -43 & $+3 \cdot 2$ \\
AN & +27 & -13 & $+5 \cdot 4$ \\
MD & +13 & -1 & $+4 \cdot 5$ \\
MC & +20 & -12 & $+2 \cdot 0$ \\
CC & +5 & -3 & $+2 \cdot 5$ \\
AM & +18 & -16 & $+7 \cdot 8$ \\
MD & +17 & -22 & $+6 \cdot 4$ \\
KC & +21 & -12 & $+0 \cdot 9$ \\
MV & +29 & -21 & $-1 \cdot 1$ \\
LP & +10 & 0 & $+4 \cdot 0$ \\
JH & +10 & +4 & $+1 \cdot 5$ \\
GH & +22 & -17 & $+5 \cdot 6$ \\
PH & +23 & -3 & $+1 \cdot 1$ \\
DB & & & $+3 \cdot 3$ \\
\hline
\end{tabular}

and they were therefore considered suitable to serve as control subjects (Table 2). This is possibly because the sugar markers become degraded by bacteria on reaching the large intestine, or because the large bowel represents a relatively small mucosal surface area compared with the small bowel.

Other probe-markers of intestinal permeability such as ${ }^{51}$ chromium-EDTA ${ }^{16}$ and polyethylene glycol $400^{17}$ have also been used to study active Crohn's disease, but the technique has not previously been used to assess the effect of an elemental diet in this condition. All the patients showed an improvement after receiving an elemental diet, and at least half achieved normal lactulose/rhamnose permeability ratios at end of the dietary period. This indicates that the increased intestinal permeability seen in this condition is a secondary rather than a primary phenomenon, and is therefore unlikely to represent a factor predisposing to the development of Crohn's disease as has been previously suggested. ${ }^{18}$

In conclusion, this study shows for the first time that an elemental diet has a direct effect on the small intestine of patients with Crohn's disease and does not merely induce a general improvement in their nutritional state.

Dr Sanderson is grateful to the Crohn's in Childhood Research Appeal for their support.

\section{References}

1 O’Morain C, Segal AM, Levi AJ, Valman HB. Elemental diet in acute Crohn's disease. Arch Dis Child 1983; 53: 44-7.

2 Sanderson IR, Udeen S, Davies PSW, Savage MO, Walker-Smith JA. Remission induced by an elemental diet in small bowel Crohn's disease. Arch Dis Child 1987; 61: 123-7.

3 Logan FR, Gillon J, Ferrington C, Ferguson A. Elemental diet reduces gastrointestinal protein loss in small bowel Crohn's disease. Gut 1981; 22: 383-7.

4 Menzies IS, Laker MF, Pounder R, et al. Abnormal intestinal permeability to sugars in villous atrophy. Lancet 1979; ii: 1107-9.

5 Ford RPK, Menzies IS, Phillips AD, Walker-Smith JA, Turner MW. Intestinal sugar permeability: relationship to diarrhoeal disease and small bowel morphology. J Pediatr Gastroenterol Nutr 1985; 4: 568-74.

6 Pearson ADJ, Eastham EJ, Laker MF, Craft AW, Nelson R. Intestinal permeability in children with Crohn's disease and coeliac disease. $\mathrm{Br} \mathrm{Med} J$ 1982; 285: 20-1.

7 Chong SKF, Blackshaw AJ, Boyle S, Williams CB, Walker-Smith JA. Histological Diagnosis of chronic inflammatory bowel disease in childhood. Gut 1985; 26: 55-9.

8 Lloyd-Still JD, Green OC. A clinical scoring system for 
chronic inflammatory bowel disease in children. Dig Dis Sci 1979; 24: 620-5.

9 Francis EM. Diets for sick children. Oxford: Blackwell, 1987.

10 Menzies IS, Mount JN, Wheeler MJ. Quantitative estimation of clinically important monosaccharrides in plasma by rapid thin layer chromatography. Ann Clin Biochem 1978; 25: 65-76.

11 Noone C, Menzies IS, Banatvala JE, Scopes JW. Intestinal permeability and lactose hydrolysis in human rotaviral gastrointeritis assessed simultaneously by noninvasive differential permeation. Eur J Clin Invest 1986; 16: $217-25$.

12 Beach RC, Menzies IS, Clayded GS, Scopes JW. Gastrointestinal permeability changes in the preterm neonate. Arch Dis Child 1982; 57: 141-5.

13 Maxton DG, Bjarnason I, Reynolds AP, Catt SD, Peters TJ, Menzies IS. Lactulose ${ }^{\mathrm{SI}} \mathrm{Cr}$-labelled ethylenediamine tetraacetate, L-rhamnose and polyethyleneglycol 400 as probe markers for assessment in vivo of human intestinal permeability. Clin Sci 1986; 71: 7180.

14 Editorial. Intestinal permeability. Lancet 1985; i: 256-8.

15 Cook GC, Menzies IS. Intestinal absorption and unmediated permation of sugars in post-infective tropical malabsorption (tropical sprue). Digestion 1986; 33: 109-16.

16 Bjarnason I. O’Morain C, Levi AJ, Peters TJ. Absorption of "stchromium-labeled ethylenediamine tetraacetate in inflammatory bowel disease. Gastroenterology 1983 ; 85: 318-22.

17 Magnusson K-E, Sundqvist T, Sjodahl R, Tagesson C. Altered intestinal permeability to low molecular weight polyethyleneglycols (PEG 400) in patients with Crohn's disease. Acta Chir Scand 1983; 149: 323-7.

18 Hollander D, Vadheim CH, Brettholz E, et al. Increased permeability in Crohn's disease patients and their relatives: an etiological factor? Annual Conference of the 87th American Gastroenterological Association, San Francisco 1986. Gastroenterology 1987; 90: 1462. 